\title{
Thyroid auto immune antibodies in children with Type-I Diabetes mellitus in relation to diabetes control
}

\author{
Muneera Fadhil Ridha', Munib Ahmed Al Zubaidi
}

\begin{abstract}
Background \& Objective: As an autoimmune disease, Type-1 diabetes mellitus (DM) may be associated with other autoimmune disorders, the presence of thyroid antibodies could be negatively impact the diabetic control. Our objective was to investigate thyroid autoimmunity in a cohort of children and adolescents with Type-1 diabetes and the Influence of the presence of thyroid autoimmune abnormalities on the control of diabetes in group of Iraqi pediatric patients with Type-I D.M.

Methods: This study was conducted at the Medical City Complex, Children Welfare Hospital, Baghdad, Iraq. This study was carried out from the first of January 2016 till the end of September 2017. Data were analyzed from 150 patients with Type-1 diabetes, aged 1-18 years who were treated and are coming for regular follow up in the diabetic clinic. Thyroid functions tests, Antibodies to thyroglobulin (anti-TG) and thyroperoxidase (anti-TPO) were measured, documented and correlated with diabetic control according to glycated haemoglobin (HbA1c) level.

Results: In the total of 150 patients, positive Antibodies to thyroglobulin (anti TG) were more in $\leq 3$ years duration group of Diabetes mellitus( DM) and negative anti TG was less in the $>3$ years duration of DM group with statistically significant results $(p=0.043)$, Regarding the distribution of thyroid antibodies $(\mathrm{AB})$ according to $\mathrm{HbA1C}$ group, there was progressive positive anti thyroperoxidase (anti TPO) titer with glycemic status, good glycemic control had the lowest positive anti TPO titer and poor glycemic control group had the highest positive anti TPO titer and the result was statistically significant $(p=0.048)$.

Conclusions: Thyroid autoimmunity may be associated with poor diabetic control and elevated TSH levels, indicating subclinical hypothyroidism that my affect the diabetic control.
\end{abstract}

KEYWORDS: Autoimmune thyroid disease, Diabetic control, Type 1 diabetes mellitus.

doi: https://doi.org/10.12669/pjms.35.4.192

How to cite this:

Ridha MF, Al-Zubaidi MA. Thyroid auto immune antibodies in children with type I Diabetes mellitus in relation to diabetes control. Pak J Med Sci. 2019;35(4):969-973. doi: https://doi.org/10.12669/pjms.35.4.192

This is an Open Access article distributed under the terms of the Creative Commons Attribution License (http://creativecommons.org/licenses/by/3.0), which permits unrestricted use, distribution, and reproduction in any medium, provided the original work is properly cited.

1. Muneera Fadhil Ridha,

2. Munib Ahmed Al Zubaidi,

1, 2: Department of Pediatrics,

University of Baghdad,

College of Medicine,

Baghdad, Iraq.

Correspondence:

Dr. Muneera Fadhil Ridha,

Specialist of Pediatric Endocrinology,

University of Baghdad, College of Medicine,

Baghdad, Iraq.

Email: saaddakhilfarhan@gmail.com

* Received for Publication:

* Revision Received:

* Revision Accepted:
December 13, 2018

May 25, 2019

May 29, 2019

\section{INTRODUCTION}

Type-I diabetes mellitus is an auto immune disease. ${ }^{1}$ It can be associated with other auto immune disorders that may influence the control of diabetes by disruption the function of respective organs. ${ }^{1}$

The prevalence of positive thyroid antibodies in children with Type-1 diabetes varies considerably between 3 and $50 \%$ in different countries, ${ }^{2}$ and the clinical significance of these antibodies remains controversial. Moreover, there has been no consensus on screening for autoimmune thyroiditis in patients with Type- 1 diabetes. ${ }^{3}$ 
Auto immune thyroid disease (AITD), is the most common auto immune disease associated with type I diabetes mellitus, The incidence is expected to be 2-4-folds higher than in general population, as Hashimoto's thyroiditis is the most common clinical form (14-28\%), the Graves' disease my noticed less frequently $(0.5-7 \%){ }^{5}$

The screening and diagnosis of AITD are based on the assessment of autoantibodies to thyroid peroxidase (anti-TPO) and thyroglobulin (antiTG). The prevalence of these autoantibodies is dependent on gender, age of patient, and age at the onset of diabetes. It also varies in different geographic regions and is known to be higher in regions with higher iodine intake. ${ }^{6,7}$

The aim of this study was to evaluate the thyroid autoantibody profile in Type- 1 diabetic patients and the Influence of the presence of thyroid autoimmune abnormalities on the control of diabetes in group of Iraqi pediatric patients with Type-I D.M.

\section{METHODS}

This study was conducted at the Medical City Complex, Children Welfare Hospital, Baghdad, Iraq. This study was carried out from the first of January 2016 till the end of September 2017. One hundred fifty children and adolescents aged during (1 year - 18 years) with Type- 1 diabetic patients coming for regular follow up in the diabetic clinic were randomly selected after taking an informed consent were included in this study. Detailed history was taken from the patients and their parents and the following data were collected: Name of the patient, contact telephone number, age (date of birth), sex, date of diagnosis of diabetes and age at diagnosis and duration of diabetes were calculated and family history of any other auto immune diseases. Glycated hemoglobin A. was estimated by using fast ion-exchange Resin Separation Method. The glycated haemoglobin (HbA1c) results for the last one year and the mean for which was calculated and considered as an indicator for glycemic control as the following: ( $\mathrm{HbA1c}=6-$ 7.9) Good control, $(\mathrm{HbA1c}=8-9.9)$ Fair control and $(\mathrm{HbA} 1 \mathrm{c}>10)$ poor control. ${ }^{8}$ Thyroid function test was measured as following: Two $\mathrm{ml}$ were taken and sent for estimation of (T3,T4 and TSH). Normal values for serum concentrations of total T3, T4, TSH Were: $1.26-2.76 \mathrm{nmol} / 1,57.9-$ $161 \mathrm{nmol} / \mathrm{ml}$, and $0.4-4.0 \mathrm{uIU} / \mathrm{ml}$ respectively.
Serum anti-thyroid peroxidase (TPO) antibody and anti-thyroglobulin antibody (TG): Was estimated by using (AESKULISA a-TPO kits, Germany) which is a solid phase enzyme immunoassay employing recombinant. Human Thyroid Peroxidase (TPO) from a eukaryotic expression system for the Quantitative and Qualitative detection of antibodies against TPO in human serum. In this study (in agreement with the ranges suggested by the manufacturer), the Normal range for anti TPO antibody was less than $87 \mathrm{IU} /$ $\mathrm{ml}$, border line (87-115) and the positive result was $>115 \mathrm{IU} / \mathrm{ml}$. For anti-thyroglobulin antibody (TG); For anti thyroglobulin; The normal range anti bodies considered normal if Antibody titer less than $80 \mathrm{IU} / \mathrm{ml}$, border line if (80-100) IU/ $\mathrm{ml}$ and Positive if antibody titer is more than $100 \mathrm{IU} / \mathrm{ml}$.

Ethical Committee: This study was authorized by Ethical Committee, Issue No.5: Children Welfare Teaching Hospital, January 1st, 2017.

\section{RESULTS}

This study included a total of 150 patients, with $100 \%$ response rate. The patients mean age and Std. Deviation was 9.72 \pm 4.28. The most common age group was 5 - 10 year constituted $46 \%$ of the patients, and the lowest age category was $<5$ year constituted $12 \%$ of the patients.

For gender distribution, females constituted $(52 \%)$ and $(48 \%)$ were males. Most of the patients $(66 \%)$ have less than three years duration of diabetes. Most of patients presented in this study had negative family history of autoimmune disease $(77.3 \%)$. Regarding glycemic control, Only 23\% of patients had strict glycemic control, while fair glycemic control constitute $36.7 \%$ of cases and $40 \%$ of patients had Poor glycemic control.

From the sera of 150 patients withType- 1 diabetic patients; The positivity of thyroid Anti TPO was $17.3 \%$ of patients while Anti TG was positive in $28 \%$ of patients and both tests was positive in $(11.6 \%)$ of patients. Based on autoantibody positivity and TSH concentration; TSH concentration was high in ten patients $(6.6 \%)$ and autoimmune thyroid disease (AITD) were newly diagnosed only in three patients $(2 \%)$.

According to distribution of thyroid $A B$ with age group, the $>10$ year age group had the highest positive anti TPO AB and the $<5$ year age group had the lowest positive anti TPO AB but the result was not statistically significant $(\mathrm{p}=0.37)$. For anti TG $A B$ the 5-10 year age group had the highest positive 
Table-I: Distribution of Anti TPO according to duration of DM, no. of patients 150 .

\begin{tabular}{lcccccc}
\hline Duration of $D M A B$ & \multicolumn{3}{c}{ Duration of DM } & p-value \\
\cline { 2 - 5 } & \multicolumn{2}{c}{$\leq 3$ year } & \multicolumn{2}{c}{$>3$ year } & \\
\cline { 2 - 5 } & No. & $\%$ & No. & $\%$ & \\
\hline \multirow{2}{*}{ Anti TPO Positive } & 14 & $14 \%$ & 12 & $24 \%$ & 0.15 \\
& Negative & 85 & $86 \%$ & 39 & $76 \%$ & \\
\hline Total & 99 & $100 \%$ & 51 & $100 \%$ & & \\
\hline
\end{tabular}

anti TG $\mathrm{AB}$ and the $<5$ year age group have the lowest positive anti $\mathrm{TG} \mathrm{AB}$ titer but the result was not statistically significant $(\mathrm{p}=0.35)$.

The distribution of thyroid $A B$ varies with the duration of DM. Although $\leq 3$ year duration group had more positive anti TPO AB titer than $>3$ year group, the result was not statistically significant $(p=0.15)$. (Table-I). Positive anti TG was more in $\leq 3$ years duration group of DM and negative anti TG was less in the $>3$ years duration of DM group with statistically significant results $(p=0.043)$ (Table-II).

Regarding the distribution of thyroid $\mathrm{AB}$ according to $\mathrm{HBAC} 1$ group, there was progressive positive anti TPO titer with glycemic status; Good glycemic control had the lowest positive anti TPO titer and poor glycemic control group had the highest positive anti TPO titer and the result was statistically significant $(p=0.048)$, as shown in (Table-III).

Although anti TG titer also shows progressive increase with bad glycemic status. But result was not statistically significant $(p=0.15)$ as shown in (Table-IV).
Table-II: Distribution of Anti TG according to duration of DM, no. of patients 150 .

\begin{tabular}{llccccc}
\hline Duration of DM AB & \multicolumn{3}{c}{ Duration of DM } & p-value \\
\cline { 3 - 5 } & & \multicolumn{2}{c}{$\leq 3$ year } & \multicolumn{2}{c}{$>$ 3 year } & \\
\cline { 3 - 6 } & & No. & $\%$ & No. & $\%$ & \\
\hline \multirow{2}{*}{ Anti TG } & Positive & 33 & $33 \%$ & 9 & $17 \%$ & 0.043 \\
& Negative & 66 & $67 \%$ & 42 & $83 \%$ & \\
\hline Total & 99 & $100 \%$ & 51 & $100 \%$ & & \\
\hline
\end{tabular}

Statistical analysis: Statistical package for social science version 20 (SPSS 20) was used for both data entry and data analysis. Discrete variable presented as number (\%). Chi-square test (or fisher exact test when appropriate) used to test the significance of association for discrete variable. P-value of $<0.05$ was considered significant.

\section{DISCUSSION}

The positivity for serum anti-TPO antibodies reported in this study was consistent with other studies. ${ }^{9-14}$ The lower percentage of positive Anti TPO than anti TG may be because that the anti TPO was more specific than Anti TGA. ${ }^{15}$ For this reason the Anti-TPO assayed by monoclonal anti body assisted RIA appears to be a more sensitive and specific marker for ATD than the conventional other tests. ${ }^{15}$ This also noted by Berg et al. in their study, and this was explained in that; the Anti TPO is associated with more elevation of TSH than ATG. ${ }^{16}$

A strong correlation exists between ThyroidAuto antibodies and the future risk of thyroid dysfunction in patients with Type-1 diabetes. ${ }^{17}$ Based on autoantibody positivity and TSH

Table-III: Distribution of Anti TPO according to HBAC1 group, no. of patients 150.

\begin{tabular}{|c|c|c|c|c|c|c|c|c|}
\hline \multirow[t]{3}{*}{ Thyroid: $A 1$} & & \multicolumn{6}{|c|}{ HBAC1 group } & \multirow[t]{3}{*}{$p$-value } \\
\hline & & \multicolumn{2}{|c|}{ Good glycemic control } & \multicolumn{2}{|c|}{ Fair glycemic control } & \multicolumn{2}{|c|}{ Poor glycemic control } & \\
\hline & & No. & $\%$ & No. & $\%$ & No. & $\%$ & \\
\hline \multirow[t]{2}{*}{ Anti TPO } & Positive & 4 & $12 \%$ & 6 & $11 \%$ & 16 & $26 \%$ & \multirow[t]{2}{*}{0.048} \\
\hline & Negative & 31 & $88 \%$ & 49 & $89 \%$ & 44 & $74 \%$ & \\
\hline Total & 35 & $100 \%$ & 55 & $100 \%$ & 60 & $100 \%$ & & \\
\hline
\end{tabular}

Table-IV: Distribution of anti TG according to HBAC1 group, no. of patients 150.

\begin{tabular}{llccccccc}
\hline Thyroid : $A B$ & & \multicolumn{9}{c}{ HBAC1 group } & p-value \\
\cline { 3 - 8 } & & \multicolumn{2}{c}{ Good glycemic control } & Fair glycemic control & Poor glycemic control & \\
\hline & & No. & $\%$ & No. & $\%$ & No. & $\%$ & \\
\hline \multirow{2}{*}{ Anti TG } & Positive & 8 & $23 \%$ & 12 & $22 \%$ & 22 & $36 \%$ & 0.15 \\
& Negative & 27 & $77 \%$ & 43 & $78 \%$ & 38 & $64 \%$ & \\
\hline Total & 35 & $100 \%$ & 55 & $100 \%$ & 60 & $100 \%$ & & \\
\hline
\end{tabular}


concentration, TSH concentration was high in $16 \%$ of the studied patients and all of them had positive auto immunity. While an overt thyroid dysfunction was observed only in three female patients with hypothyroidism, this is in consistent with other literatures which showed that ATD more often produces signs of hypothyroidism (Hashimoto's thyroiditis) and less frequently of hyperthyroidism (Graves' disease or the hyperactive phase of Hashimoto's thyroiditis). ${ }^{18,19}$ Furthermore, the long period of autoimmunity makes the clinical diagnosis of thyroid autoimmune disease difficult because it often runs in subclinical state. Measurements of thyroid functions tests in clinically suspected cases or in patients with positive Thyroid antibodies (TAA) would confirm the disease. ${ }^{20}$ Although positive anti TPO was the same in both duration group of DM, the less 3 year group shows more positive anti TG titer with statistically significant results $(p=0.043)$. This is comparable with other reports ${ }^{21}$, which showed a decrease in the concentrations of thyroid antibodies with increasing duration of diabetes, this may be explained in part by increase seroconversion peaks of thyroid antibodies around the puberty, at which time the thyroid gland undergoes remodeling. ${ }^{22}$ In this study, there is significant correlation between positive result of serum antibodies and poor glycemic control. The associated autoimmune disease may influence the control of diabetes by impairing function of the respective organ. Moreover, thyreotoxi-cosis may worsen the metabolic control of diabetes and increase the need for increased insulin dosage, and hypothyroidism can lead to increased frequency of hypoglycemic episodes in diabetic patients. ${ }^{22,23}$ Metwalley KA et al. in their study in Egypt showed that Diabetic patients with hypothyroidism had higher HbA1c than those without hypothyroidism. ${ }^{24}$

\section{CONCLUSION}

The screening of autoantibodies in Type-1 diabetic patients could reveal subclinical cases AITD, but its predictive value for progression to clinical manifestation is limited. The follow-up of patients with positive autoantibodies is necessary because further deterioration of diabetic control and dysfunction of the respective organs may occur.

Grant Support \& Financial Disclosures: None.

\section{REFERENCES}

1. Ka Young Oh, Yun Hee Kim, Eun Mi Yang, Chan Jong Kim. Frequency of Diabetes and Thyroid Autoantibodies in Patients with Type 1 Diabetes and Their Siblings. Chonnam Med J. 2016;52(2):136-140. doi: 10.4068/cmj.2016.52.2.136

2. Palma CCSSV, Pavesi M, Nogueira VG, Clemente ELS, Vasconcellos MdFBMP, Pereira Jr. LC, et al. Prevalence of thyroid dysfunction in patients with diabetes mellitus. Diabetol Metab Syndr. 2013;5:58. doi: 10.1186/1758-5996-5-58.

3. Burek CL, Rose NR, Guire KE, Hoffmann WH. Thyroid autoantibodies in black and white children and adolescents with type 1 diabetes mellitus and their firstdegree relatives. Autoimmunity. 1990;7:157-167. doi: $10.3109 / 08916939008993388$

4. Hage M, Zantout MSM, Azar ST. Tyroid disorders and diabetes mellitus. J Thyroid Res. 2011;2011:439463. doi: $10.4061 / 2011 / 439463$.

5. Nordyke RA, Gilbert FI, Miyamoto LA, Fleury KA. The superiority of antimicrosomal over anti thyroglobulin antibodies for detecting Hashimoto's thyroiditis. Arch Intern Med.1993;153:862-865.

6. Feldt-Rasmussen U. Analytical and clinical performance goals for testing autoantibodies to thyroperoxidase, thyroglobulin, and thyrotropin receptor. Clin Chem.1996;42:160-163.

7. Mariotti S, Caturegli P, Piccolo P, Barbesino G, Pinchera A. Antithyroid peroxidase autoantibodies in thyroid diseases. J Clin Endocrinol Metab. 1990;71:661-669. doi: 10.1210/jcem71-3-661

8. Kliegman, Behrman, Jenson, Stanton. The endocrine system. Part XXVI. chapter 589, diabetes mellitus, page 2777. Nelson text book of pediatrics, 20th edition.

9. Abdullah MA, Salman H, Bahakim H, Gad al Rab MO, Halim K, Abanamy A. Antithyroid and other organ specific antibodies in Saudi Arabia diabetic and normal children. Diabet Med. 1990;7:50-52. doi: 10.15537/ smj.2016.4.13571.

10. Lopez Medina JA, Lopez-Jurado Romero de la Cruz R, Delgado Garcia A, Espigares Martin R, Barrionuevo Porras JL, Ortega Martos L. Beta-cell, thyroid and celiac autoimmunity in children with type 1 diabetes. An Pediatr (Barc). 2004;61:320-325.

11. Sharifi F, Ghasemi L, Mousavinasab N. Thyroid Function and anti-thyroid antibodies in Iranian patients with type 1 diabetes mellitus: influences of age and sex. Iran J Allergy Asthma Immunol. 2008;7:31-36.

12. Chang CC, Huang CN, Chuang LM. Autoantibodies to thyroid peroxidase in patients with type 1 diabetes in Taiwan. Taiwan(Eur J Endocrinol).1998;139(1):44-48.

13. Frasier SD, Penny R, Snyder R, Goldstein I, Graves D. Antithyroid antibodies in Hispanic patients with type I diabetes mellitus. Prevalence and significance. Am J Dis Child. 1986;140:1278-1280. doi: 10.1001/ archpedi.1986.02140260080032.

14. Peczynska J, Urban M, Glowinska-Olszewska B, Florys B. Prevalence of thyroid diseases in children and adolescents with diabetes type 1. Ped Endocrinol. 2006;5(1):33-38. doi: 10.1155/2016/6219730.

15. Kordonouri O, Klinghammer A, Lang EB, Gruters-Kieslich A, Grabert M, Holl RW. Thyroid autoimmunity in children and adolescents with type 1 diabetes: a multicenter survey. Diabet Care. 2002;25(8):1346-1350. doi: 10.2337/ diacare.25.8.1346 
16. Padbergs Heller K, Usadalk $H$. One year prophylactic treatment of euthyroid hashimotoesthyroiditis with levothyroxine, is there is any benefit? Thyroid 2011;11:249-255.

17. Denzer C, Karges B, Nake A, Rosenbauer J, Schober E, Schwab KO, et al. Subclinical hypothyroidism and dyslipidemia in children and adolescents with type 1 diabetes mellitus. Euro J Endocrinol. 2013;168(4):601-608. doi: 10.1530/EJE-12-0703.

18. Cinek O, Pechov M, Kolouskov S, Hork I, Sedlkov P, Sumnk $\mathrm{Z}$, et al. Autoantibodies to GAD65, IA2 and insulin in Czech children with type 1 diabetes (in Czech). Cas lek ces 2000;139:599-603.

19. Vondra K, Vrbikova J, Ivaskoval E, Pobisova Z, PorsovaDutoit I, Skibova J, et al. Thyroglobulin and microsome autoantibodies and their clinical significance in adult type I diabetics (in Czech). Vnitr Lek. 1996;42:767-771.

20. Yamada K, Yuan X, Inada C, Hayashi H, Koyama K, Ichikawa $\mathrm{F}$, et al. Combined measurements of GAD62 and ICA512 antibodies in acute onset and slowly progressive IDDM. Diabet Res Clin Pract. 1997;35:91-98.

21. Mariotti S, Caturegli P, Piccolo P, Barbesino G, Pinchera A. Antithyroid peroxidase autoantibodies in thyroid diseases. J Clin Endocrinol Metab. 1990;71:661-669. doi: 10.1210/jcem-71-3-661.
22. Prazny M, Skrha J, Limanova Z, Vanickova Z, Hilgertova J, Prazna J, et al. Screening for Associated Autoimmunity in Type 1 Diabetes Mellitus With Respect To Diabetes Control. Physiol Res. 2005;54:41-48.

23. Grant RW, Kirkman MS. Trends in the evidence level for the American Diabetes Association's 'Standards of Medical Care in Diabetes' from 2005 to 2014. Diabet Care. 2015;38(1):6-8. doi: $10.2337 / \mathrm{dc} 14-2142$.

24. Metwalley KA, El-Saied ARAH. Thyroid abnormalities in Egyptian children and adolescents with type 1 diabetes mellitus: A single center study from Upper Egypt. Indian J Endocrinol Metab. 2014;18(5):637-641.

\section{Author`s Contribution:}

MF: Conceived, designed, statistical analysis, editing of manuscript, data collection and manuscript writing.

MZ: did review and final approval of manuscript. 